https://helda.helsinki.fi

\title{
Publication bias in meta-analysis of ascorbic acid for postoperative atrial fibrillation
}

\section{Hemilä, Harri}

2017-03-15

Hemilä , H 2017 , ' Publication bias in meta-analysis of ascorbic acid for postoperative atrial fibrillation ' , American Journal of Health-System Pharmacy , vol. 74 , no. 6 , pp. 372-373 . https://doi.org/10.2146/ajh

http://hdl.handle.net/10138/312602

https://doi.org/10.2146/ajhp160999

acceptedVersion

Downloaded from Helda, University of Helsinki institutional repository.

This is an electronic reprint of the original article.

This reprint may differ from the original in pagination and typographic detail.

Please cite the original version. 
Publication bias in meta-analysis of ascorbic acid for postoperative atrial fibrillation

\section{Harri Hemilä}

Harri Hemilä

Department of Public Health

University of Helsinki, Helsinki, FINLAND

harri.hemila@helsinki.fi

https://www.mv.helsinki.fi/home/hemila/

https://www.mv.helsinki.fi/home/hemila/VitC AF.htm Papers on vitamin C and AF \& ICU

This is a manuscript version of a letter-to-the-editor published as

Hemilä H.

Publication bias in meta-analysis of ascorbic acid for postoperative atrial fibrillation.

Am J Health Syst Pharm. 2017 Mar 15;74(6):372-373.

https://doi.org/10.2146/ajhp160999

https://www.ncbi.nlm.nih.gov/pubmed/28274978

This letter comments a meta-analysis published as

Baker WL, Coleman CI.

Meta-analysis of ascorbic acid for prevention of postoperative atrial fibrillation after cardiac surgery.

Am J Health Syst Pharm. 2016 Dec 15;73(24):2056-2066.

https://doi.org/10.2146/ajhp160066

https://www.ncbi.nlm.nih.gov/pubmed/27806938 
Baker and Coleman [1] conducted a meta-analysis of 11 studies on ascorbic acid for the prevention of postoperative atrial fibrillation (POAF). They concluded that perioperative administration of ascorbic acid reduces the frequency of POAF. However, the results of 2 rather large randomized controlled trials (RCTs) conducted in the United States were missing from their meta-analysis.

An RCT of ascorbic acid for POAF is registered with ClinicalTrials.gov, but the results of the study have not been published.[2] That RCT's study chair told me that he and his colleagues did not seek publication because their findings were negative (Kramer RS, personal communication, 2016 Mar 23). He sent me the results of the RCT, which are included in a meta-analysis I subsequently conducted (table).

In a review article, Van Wagoner [6] briefly described an unpublished RCT, conducted by his research group, of ascorbic acid for POAF. I contacted Dr. Van Wagoner, who also said that the study results were not submitted for publication because they were negative (Van Wagoner DR, personal communication, 2015 Sep 26). He sent me the study findings, which also appear in the table.

These instances of publication not being sought because of negative results illustrate publication bias. Furthermore, a small trial conducted by Healy et al.,[4] whose results appeared in abstract form only, was omitted from Baker and Coleman's [1] meta-analysis. Baker and Coleman used a statistical test to determine whether there might be publication bias in their meta-analysis and stated that "no significant publication bias was noted (Egger's $p=0.13$ )." However, such a theoretical calculation does not provide definitive evidence about whether publication bias actually does or does not exist. The omission of the aforementioned unpublished studies illustrates that publication bias did exist in Baker and Coleman's meta-analysis and flawed their estimate of the effect of ascorbic acid.

Baker and Coleman stated that "only RCTs that compared ascorbic acid with a placebo or other control were included" in their review, but they included the study by Carnes et al. [7] even though it was not an RCT. Strangely enough, Baker and Coleman stated that "one study did not involve random sequence generation" and referred to the study of Carnes et al., yet that study was included in their review.

To my knowledge, the table herein shows all RCTs involving ascorbic acid that have been conducted in the United States. In total, 889 participants were included in these trials, and the number of patients with POAF was 268. The three RCTs missing from Baker and Coleman's metaanalysis - the first, second, and fourth entries in my table — contribute 680 participants and 203 cases of POAF, and their combined weight in my meta-analysis is $74.6 \%$. Thus, the majority of RCT data from the U.S. trials are missing from the meta-analysis of Baker and Coleman. My metaanalysis showed a narrow 95\% confidence interval (CI) around the null effect. The lower limit of that CI indicates that it is unlikely that ascorbic acid reduces the occurrence of POAF by more than $14 \%$.

Baker and Coleman's analysis of 11 studies, 1 of which was not an RCT,[7] yielded an odds ratio of 0.44 , indicating that ascorbic acid might decrease the overall frequency of POAF. That calculation of average effect is reasonable, but given that the 5 U.S. trials, taken together, showed no benefit from ascorbic acid, Baker and Coleman's results indicate that the benefit occurred in non-U.S. trials. Eight of the 11 studies included by Baker and Coleman were conducted outside of the United States (mainly in Iran and Greece), and their pooled result indicates a reduction in the risk of POAF by $44 \%\left(95 \%\right.$ CI, 33-53\%; $\left.\mathrm{p}=10^{-9}\right)$. The $95 \%$ CIs of the 5 U.S. and the 8 non-U.S. trials are 
definitely incompatible, which implies that a single estimate of effect cannot be consistent with both groups of RCTs.

Panagiotou et al. [8] compared the efficacy of several treatments in less-developed and moredeveloped countries and found that, in many cases, the benefits were significantly greater in the less-developed countries. Ascorbic acid might have effects on POAF risk in less-developed countries but not in more-developed countries. On the basis of the 5 RCTs conducted in the United States, there seems to be no justification to conduct further similar trials in the United States, with perhaps the exception of studying patients who have particularly low ascorbic acid levels. There is, however, strong evidence to encourage further research on ascorbic acid and POAF in lessdeveloped countries.

Table. Meta-analysis of U.S. Trials of Ascorbic Acid for Preventing POAF

\begin{tabular}{|l|c|c|c|c|c|c|}
\hline & \multicolumn{2}{|c|}{ Ascorbic Acid Group } & \multicolumn{2}{|c|}{ Control Group } & & \\
\hline Investigators & $\mathbf{N}$ & $\begin{array}{c}\text { No. POAF } \\
\text { Cases }\end{array}$ & $\mathbf{N}$ & $\begin{array}{c}\text { No. POAF } \\
\text { Cases }\end{array}$ & $\begin{array}{c}\text { Study } \\
\text { Weight (\%) }\end{array}$ & RR (95\% CI) \\
\hline Donovan et al.[2], $^{\text {a }}$ & 150 & 58 & 154 & 48 & 36.0 & $1.24(0.91-1.69)$ \\
\hline Van Wagoner et al. $^{\text {a }}$ & 177 & 44 & 169 & 41 & 31.9 & $1.02(0.71-1.48)$ \\
\hline Bjordahl et al.[3] & 89 & 27 & 96 & 29 & 21.3 & $1.00(0.65-1.56)$ \\
\hline Healy et al.[4] & 19 & 5 & 11 & 7 & 6.7 & $0.41(0.17-0.99)$ \\
\hline Colby et al.[5] & 13 & 4 & 11 & 5 & 4.1 & $0.68(0.24-1.92)$ \\
\hline & & & & & & \\
\hline Pooled (fixed effect) & 448 & 138 & 441 & 130 & 100 & $1.04(0.86-1.27)$ \\
\hline
\end{tabular}

The individual relative risk (RR) values and the pooled RR were calculated using the RevMan program of the Cochrane collaboration. There is no significant heterogeneity among the 5 studies $\left(\mathrm{I}^{2}=35 \%\right.$ and $\mathrm{p}=0.18$ in the test of heterogeneity).

POAF $=$ postoperative atrial fibrillation

$\mathrm{CI}=$ confidence interval

${ }^{a}$ Data were provided by the investigators and appear here with their permission. 


\section{References}

1. Baker WL, Coleman CI.

Meta-analysis of ascorbic acid for prevention of postoperative atrial fibrillation after cardiac surgery.

Am J Health-Syst Pharm 2016; 73:2056-66.

https://doi.org/10.2146/ajhp160066

2. ClinicalTrials.gov.

Prophylaxis to reduce postoperative atrial fibrillation in cardiac surgery (2012).

https://clinicaltrials.gov/ct2/show/NCT00953212

3. Bjordahl PM, Helmer SD, Gosnell DJ et al.

Perioperative supplementation with ascorbic acid does not prevent atrial fibrillation in coronary artery bypass graft patients.

Am J Surg 2012; 204:862-7.

https://doi.org/10.1016/j.amjsurg.2012.03.012

4. Healy RM, Day D, Van Gorder C.

Ascorbic acid utilization for atrial-fibrillation prophylaxis post coronary-arterybypass graft and valve replacement surgeries: an interim analysis of a prospective, randomized study (abstract 285). Pharmacotherapy 2010; 30:445e-446e.

https://www.mv.helsinki.fi/home/hemila/CAF/Healy 2010 Abstract.pdf

5. Colby JA, Chen WT, Baker WL et al.

Effect of ascorbic acid on inflammatory markers after cardiothoracic surgery.

Am J Health-Syst Pharm 2011; 68:1632-9.

https://doi.org/10.2146/ajhp100703

6. Van Wagoner DR.

Oxidative stress and inflammation in atrial fibrillation: role in pathogenesis and potential as a

therapeutic target.

J Cardiovasc Pharmacol 2008; 52:306-13.

https://doi.org/10.1097/FJC.0b013e31817f9398

7. Carnes CA, Chung MK, Nakayama T et al.

Ascorbate attenuates atrial pacing-induced peroxynitrite formation and electrical remodeling and decreases the incidence of postoperative atrial fibrillation.

Circ Res 2001; 89:E32-8.

https://doi.org/10.1161/hh1801.097644

8. Panagiotou OA, Contopoulos-Ioannidis DG, Ioannidis JP.

Comparative effect sizes in randomised trials from less developed and more developed countries: metaepidemiological assessment.

BMJ 2013; 346:f707.

https://doi.org/10.1136/bmj.f707

https://www.ncbi.nlm.nih.gov/pmc/articles/PMC3570069 